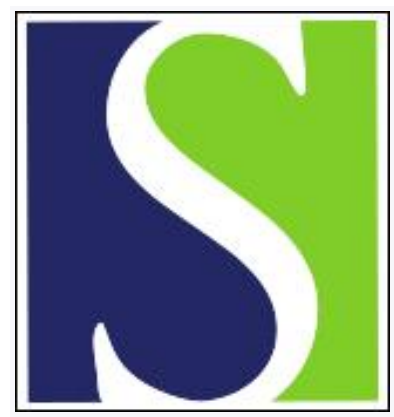

Scand J Work Environ Health 2017;43(1):75-85

https://doi.org/10.5271/sjweh.3594

Published online: 16 Sep 2016, Issue date: 01 Jan 2017

Time trends in incidence and prevalence of carpal tunnel syndrome over eight years according to multiple data sources: Pays de la Loire study

by Roquelaure Y, Chazelle E, Gautier L, Plaine J, Descatha A, Evanoff B, Bodin J, Fouquet N, Buisson C

Using data from the Pays de la Loire surveillance program of musculoskeletal disorders and National Health Insurance system, we revealed a decreasing time trend for carpal tunnel syndrome (CTS) over an 8-year period. These decreasing trends were statistically significant for surgical cases of CTS and uncompensated work-related CTS, but not for CTS compensated as an occupational disease, while the variation in clinically diagnosed CTS among the COSALI cohort was not statistically significant.

Affiliation: Equipe d'épidémiologie en santé au travail et ergonomie (ESTER), Faculté de médecine, rue Haute de Reculée, 49045 Angers, France. yves.roquelaure@univ-angers.fr

Refers to the following texts of the Journal: 2001;27 suppl 1:1-102 2009;35(5):342-348 2013;39(2):155-163 2013;39(5):495-505

Key terms: carpal tunnel syndrome; CTS; incidence; occupational disease; Pays de la Loire study; prevalence; surgery; surveillance; time trend

This article in PubMed: www.ncbi.nlm.nih.gov/pubmed/27631820

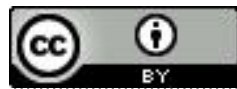




\title{
Time trends in incidence and prevalence of carpal tunnel syndrome over eight years according to multiple data sources: Pays de la Loire study
}

\author{
by Yves Roquelaure, MD, 1,2 Emilie Chazelle, MD, ${ }^{3}$ Ludivine Gautier, MSc, ${ }^{2}$ Julie Plaine, MSc, ${ }^{3}$ Alexis \\ Descatha, MD, ${ }^{4}$ Bradley Evanoff, MD, ${ }^{5}$ Julie Bodin, MSc, ${ }^{1,2}$ Natacha Fouquet, MSc, ${ }^{2,3}$ Catherine Buisson MD ${ }^{3}$
}

\begin{abstract}
Roquelaure Y, Chazelle E, Gautier L, Plaine J, Descatha A, Evanoff B, Bodin J, Fouquet N, Buisson C. Time trends in incidence and prevalence of carpal tunnel syndrome over eight years according to multiple data sources: the French Pays de la Loire study. Scand J Work Environ Health. 2017;43(1):75-85. doi:10.5271/sjweh.3594
\end{abstract}

\begin{abstract}
Objective The aim of this study was to describe time trends of incidence/prevalence of carpal tunnel syndrome (CTS), one of the most common musculoskeletal disorders, in a French region over an 8-year period.

Methods Three independent data sources were analyzed for the population of the Pays de la Loire region aged 20-59 between 2004 and 2011: hospital discharge records for "surgically treated CTS" (SURG-CTS), the social insurance data on "CTS compensated for as an occupational disease" (OD-CTS), and the regional surveillance program of "work-related diseases" (WRD-CTS). Case counts were analyzed using negative binomial regression models and cubic spline curves with year as the main covariate.
\end{abstract}

Results The annual incidence rates of SURG-CTS decreased from 3.35 to 2.98 per 1000 person-years over the 8-year period, with an overall declining trend $[-2.00 \%, 95 \%$ confidence interval $(95 \% \mathrm{CI})-3.07--0.91 \%)$, $\mathrm{P}<0.001]$. The annual incidence rate of OD-CTS per 1000 person-years decreased (from 1.52 to 1.01 ) between 2004 and 2007 and increased after 2007 (from 1.45 to 2.34), with an overall gain of 54\% during the study period. The prevalence rate of WRD-CTS decreased from 5.04 (95\% CI 3.90-6.13) to 3.08 (95\% CI 2.11-4.06) per 1000 employed person-years, with a non-significant trend between 2004 and 2011.

Conclusion The study showed declining rates of SURG-CTS and WRD-CTS in the population of working age between 2004 and 2011, contrasting with increasing rate of OD-CTS after 2007. More research and surveillance data are needed to assess whether and to what extent the declining rates of CTS are actually attributable to improvement in working conditions and/or to non-occupational factors.

Key terms CTS; occupational disease; surgery; surveillance; work-related disease.

Carpal tunnel syndrome (CTS) is one of the most common musculoskeletal disorders of the upper-extremities (UE-MSD) in working populations (1-4). As in many industrialized countries, CTS is a leading cause of surgery and occupational diseases (OD) in France (5-6).

Certain personal characteristics (eg, age and gender) and medical conditions (eg, obesity and diabetes mellitus) increase the risk of CTS (7-8), and certain working conditions exposing workers to biomechanical constraints are also risk factors for CTS (eg, repetitive movements, handarm transmitted vibration, forceful manual exertion, and bending/twisting of the wrist) $(1,3,9,10)$. A substantial number of cases of CTS diagnosed in the population of working age are thus related to personal characteristics rather than working conditions and would have occurred in the workforce whether workers were exposed to jobs at high risk of CTS or not. Other numbers of cases of CTS occurring in excess among workers in jobs at high risk in

1 INSERM, Research Institute for Environmental and Occupational Health (IRSET), Epidemiology in Occupational Health and Ergonomics (ESTER) Team, Angers, France.

2 University of Angers, Epidemiology in Occupational Health and Ergonomics (ESTER) Team, Angers, France.

3 Santé Publique France, the French Public Health Agency, Direction of Occupational Health, Saint-Maurice, France.

4 INSERM UMS 011, Population Based Epidemiological cohorts Unit and University Versailles St-Quentin, Versailles, France.

5 Washington University School of Medicine, Division of General Medical Sciences, St. Louis, MO, USA.

Correspondence to: Prof. Yves Roquelaure, Equipe d'épidémiologie en santé au travail et ergonomie (ESTER), Faculté de médecine, rue Haute de Reculée, 49045 Angers, France. [E-mail: yves.roquelaure@univ-angers.fr] 
comparison with the general population can be considered as "attributable to work". The proportion increases with the relative risk of CTS in such jobs and can be estimated by the attributable fraction of risk. Using data from a pilot study on surgically treated CTS (SURG-CTS) involving 1500 people (1053 women, 447 men) undergoing surgical release in two large hand surgery settings of the Pays de la Loire region in 2002-2003, we estimated the average population attributable fraction of SURG-CTS to work to be $24.2 \%$ [ $95 \%$ confidence interval $(95 \% \mathrm{CI}) 16.8-30.8]$ after adjustment for the main personal risk factors (age, gender, body mass index and diabetes mellitus) (11). Higher values of unadjusted population attributable fraction of CTS (defined by neurophysiological criteria) were found in selected occupational categories, such as male blue-collar workers $(50 \%, 95 \%$ CI $41-57)$ (12).

Reduction of the incidence of CTS is a priority for occupational health due to its human and social as well as economic costs (13). Several recent studies have suggested a decline in the incidence of work-related MSD in the North-American and European working populations $(14,15)$. However, there is little information regarding the non-occupational and occupational factors influencing observed time trends in the incidence of CTS (14-16). Reduction of the prevalence of well-documented, non-occupational risk factors for CTS in the population of working age, such as obesity, might result in a decline in the incidence of CTS, whether the cases are attributable to work or not. Improvement of working conditions by reducing exposure to occupational risk factors might also contribute to reducing the incidence of CTS. The impact will depend on the proportion of cases attributable to work and the combined effects of occupational and non-occupational risk factors when present in combination.

Surveillance programs are needed to monitor time trends and assess the efficacy of preventive interventions (15). Workers' compensation claims are commonly used to describe time trends in CTS, but underestimate the true incidence of disease (17) and do not capture cases of CTS classified as not related to work. Few reliable indicators of the frequency of CTS are available, for example surgical release of the median nerve, and none can assess the true frequency accurately (18). Santé publique France, the French Public Health Agency, therefore implemented an epidemiological UE-MSD surveillance program in the Pays de la Loire region (Loire Valley area, west central France) based on multiple data sources (18).

To demonstrate whether a decline in the frequency of UE-MSDs has occurred in the French Pays de la Loire region or not, we used data from the surveillance program for CTS to evaluate time trends of prevalence and incidence of CTS over an 8-year period according to multiple sources of information.

\section{Methods}

\section{Study design}

This descriptive study is based on information from three independent data sources collected between 2004 and 2011 covering the working age population (20-59 years) of the Pays de la Loire region. These data sources included: (i) the hospital discharge records for SURGCTS cases in the general population; (ii) the social insurance database on "CTS compensated for as occupational disease" (OD-CTS) for the region's salaried workers; and (iii) the database of the region's "work-related diseases" (WRD) surveillance program among the region's salaried workers;

\section{Population}

According to census data (19), the general population of the Pays de la Loire region increased annually by about $2 \%$ between 2004 and 2011, reaching more than 3.5 million inhabitants in 2011. A total of 1435321 people were working in 2004 (including 1295041 salaried workers and 140280 non-salaried workers), representing about $6 \%$ of the French working population, with a diversified socioeconomic structure similar to that of France as a whole. The working population increased during the study period, with overall gains of salaried workers of $58947(+5 \%)$ and non-salaried workers of 11807 (+8\%) (19).

\section{Sources of surveillance data and outcomes}

The Pays de la Loire surveillance program has been described in detail elsewhere (18), and we therefore present the main features of each source of data and definitions of the sentinel events used to identify CTS cases.

SURG-CTS. The hospital discharge database of the French National Medical Information Systems Program (PMSI) was analyzed to include all patients living in the region having undergone surgery for CTS (WHO ICD-10 code G 56.0) during the years of interest. The search criteria used were the two specific codes for CTS surgery: "carpal tunnel syndrome release" and "carpal tunnel syndrome ambulatory release".

OD-CTS. In France, CTS can be compensated for by the social insurance funds for salaried workers when the medical and exposure criteria (defined by "Compensation Table $\mathrm{N}^{\circ}$ 57C", WHO ICD-10 code G 56.0) are met. The diagnosis of CTS should be confirmed by the physicians of the social insurance, verifying the presence at examination or in the medical records of clinical signs of CTS and positive electrophysiological findings and/or surgical 
release of the median nerve. Moreover, workers should have been usually exposed to repetitive movements of the hand and wrist at the workplace before the diagnosis of CTS $(6,17)$. Using the regional database of the National Health Insurance system (Caisse nationale de l'assurance maladie des travailleurs salariés, CNAM-TS), all CTS recognized as OD and compensated for at least one day of sick leave were analyzed. The French compensation system registered OD-CTS for each wrist separately; workers with bilateral CTS were counted as two cases.

WRD-CTS. In France, all salaried workers undergo a mandatory, regularly scheduled health examination by an occupational physician (OP). A network of OP volunteered to participate in the WRD surveillance program during a randomly predefined 2-week period every six months each year from $2004(17,20)$. OP-diagnosed WRD-CTS cases were assessed among the region's workers included in the WRD program. OP collected data on all workers during the mandatory regularly scheduled health examinations performed during the 2-week periods. The CTS (WHO ICD-10 code G 56.0) diagnosed were classified as "work-related" by the OP during the surveillance examination on the basis of their personal judgement of the occupational and non-occupational risk factors independently of any worker compensation claim. All workers with notified WRD-CTS from all the salaried workers seen during the 2-week period under consideration were counted as cases. Bilateral cases of WRD-CTS notified by OP counted as one case. Information was collected on all WRD cases notified during the same period, including MSD and other WRD.

\section{Statistical analysis}

The data of the last available census of the general population was used as denominator to compute the annual incidence rate of SURG-CTS in the general population of the region, ie, 1999 census for data until 2007 and 2008 census data thereafter. The incidence rates of OD-CTS were computed with reference to the number of salaried workers of working age living in the region covered by the social insurance funds for salaried workers (CNAM-TS). The prevalence rate of WRD-CTS was computed by dividing the total number of WRD-CTS diagnosed by the number of workers surveyed during the 2-week period. The incidence rate of SURG-CTS and OD-CTS and prevalence rate of WRD-CTS were calculated for 1000 person-years, hypothesizing that all salaried workers were employed full-time during the entire year. Incidence/prevalence rates were computed according to age, gender, occupational categories and industry sectors when the information was available. Annual percent changes of the incidence/prevalence rates were computed (14).
Two methods were used to estimate trends in incidence/prevalence of CTS (SURG-CTS, OD-CTS and WRD-CTS) over the study period after graphical analysis of the data. Firstly, the non-parametric Kendall rank correlation test, which does not require any distribution hypothesis, was calculated between years and annual prevalence/incidence rate of CTS. Secondly, negative binomial regression models were used to estimate the overall average annual change in incidence/prevalence of CTS with year as the main predictor of interest. The negative binomial is a generalization of the Poisson model which is particularly useful for such over-dispersed data (15). Time (year) was treated as a continuous variable for SURG-CTS and with a cubic spline for OD-CTS and WRD-CTS (21). The spline models were based on the observed "best fit" of the data and a visual exploration of the data was conducted to determine the knot(s): one in 2007 for OD-CTS and two in 2007 and 2009 for WRD-CTS. The log of the reference population size was included in the regression model as an "offset" to take into account variations in the population size each year (15).

\section{Results}

\section{Trends in incidence of SURG-CTS}

The annual incidence rates of SURG-CTS per 1000 person-years decreased from 3.35 to 2.98 over the 8 -year period (Kendall $\tau$ : $-0.571, \mathrm{P}=0.048$ ) (table 1 and figure 1a) with some annual variation. The overall decrease was $11 \%$, and annual percent change ranged from $-9 \%$ in 2007 to $+6 \%$ in 2008 . The negative binomial regression model showed a statistically significant decreasing general trend $[-2.00 \%(95 \% \mathrm{CI}-3.07--0.91 \%), \mathrm{P}<0.001)$ in the annual incidence rate for SURG-CTS (figure 2a). Incidence rates and decreasing trends were higher among women (from 4.80 to 4.16 cases per 1000 personyears, overall decrease of $13 \%$ ) than men (from 1.90 to 1.79 cases per 1000 person-years, overall decrease of $6 \%$ ) (figure 1b). Higher incidence rates were observed in inhabitants aged $\geq 45$ years, but the decreasing trends were consistent for all age groups.

\section{Trends in incidence of OD-CTS}

Between 1279 and 2312 cases of OD-CTS received compensation each year (table 2), representing about $40 \%$ of all compensated UE-MSD cases. The annual incidence rate of OD-CTS decreased (from 1.52 to 1.01 per 1000 employed person-years) between 2004 and 2007, but increased since 2008 (from 1.45 to 2.34 per 1000 employed person-years) (figure 1a), with an overall gain of $54 \%$ during the study period (Kendall 
Table 1. Annual incidence rate (IR) of surgically treated carpal tunnel syndrome (SURG-CTS) per 1000 person-years in the general population of working age. Pays de la Loire, France, 2004-2011

\begin{tabular}{|c|c|c|c|c|}
\hline Year & SURG-CTS & $\begin{array}{c}\text { Region } \\
\text { inhabitants }\end{array}$ & IR & $\begin{array}{c}\text { Annual } \\
\text { change } \\
(\%)\end{array}$ \\
\hline \multicolumn{5}{|l|}{2004} \\
\hline Total & 6033 & 1802712 & 3.35 & \\
\hline \multicolumn{5}{|l|}{ Gender } \\
\hline Men & 1715 & 902680 & 1.90 & \\
\hline Women & 4318 & 900032 & 4.80 & \\
\hline \multicolumn{5}{|c|}{ Age (years) } \\
\hline $20-44$ & 2339 & 1130705 & 2.07 & \\
\hline $45-59$ & 3694 & 672009 & 5.50 & \\
\hline \multicolumn{5}{|l|}{2005} \\
\hline Total & 6331 & 1820922 & 3.48 & +3.9 \\
\hline \multicolumn{5}{|l|}{ Gender } \\
\hline Men & 1666 & 911452 & 1.83 & -3.7 \\
\hline Women & 4665 & 909470 & 5.13 & +6.9 \\
\hline \multicolumn{5}{|c|}{ Age (years) } \\
\hline $20-44$ & 2270 & 1131048 & 2.01 & -3.0 \\
\hline $45-59$ & 4061 & 689877 & 5.89 & +7.1 \\
\hline \multicolumn{5}{|l|}{2006} \\
\hline Total & 5868 & 1833388 & 3.20 & -8.1 \\
\hline \multicolumn{5}{|l|}{ Gender } \\
\hline Men & 1620 & 917561 & 1.77 & -3.3 \\
\hline Women & 4248 & 915827 & 4.64 & -9.6 \\
\hline \multicolumn{5}{|c|}{ Age (years) } \\
\hline $20-44$ & 2198 & 1131972 & 1.94 & -3.3 \\
\hline $45-59$ & 3670 & 701418 & 5.23 & -11.1 \\
\hline \multicolumn{5}{|l|}{2007} \\
\hline Total & 5342 & 1835873 & 2.91 & -9.1 \\
\hline \multicolumn{5}{|l|}{ Gender } \\
\hline Men & 1567 & 918546 & 1.71 & -3.4 \\
\hline Women & 3775 & 917328 & 4.12 & -11.2 \\
\hline \multicolumn{5}{|c|}{ Age (years) } \\
\hline $20-44$ & 1995 & 1130794 & 1.76 & -9.1 \\
\hline $45-59$ & 3347 & 705081 & 4.75 & -9.3 \\
\hline \multicolumn{5}{|l|}{2008} \\
\hline Total & 5644 & 1834956 & 3.08 & +5.8 \\
\hline \multicolumn{5}{|l|}{ Gender } \\
\hline Men & 1644 & 917686 & 1.79 & +4.7 \\
\hline Women & 4000 & 917270 & 4.36 & +5.8 \\
\hline Age (years & & & & \\
\hline $20-44$ & 2160 & 1129094 & 1.87 & +5.9 \\
\hline $45-59$ & 3534 & 705864 & 5.01 & +5.5 \\
\hline 2009 & & & & \\
\hline Total & 5469 & 1834988 & 2.98 & -3.3 \\
\hline Gender & & & & \\
\hline Men & 1623 & 917349 & 1.77 & -1.1 \\
\hline Women & 3846 & 917639 & 4.19 & -3.9 \\
\hline Age (years & & & & \\
\hline $20-44$ & 2004 & 1127257 & 1.78 & -4.9 \\
\hline $45-59$ & 3465 & 707732 & 4.90 & -2.2 \\
\hline 2010 & & & & \\
\hline Total & 5539 & 1834412 & 3.02 & +1.3 \\
\hline Gender & & & & \\
\hline Men & 1669 & 916669 & 1.82 & +2.8 \\
\hline Women & 3870 & 917743 & 4.22 & +0.7 \\
\hline Age (years & & & & \\
\hline $20-44$ & 2108 & 1124441 & 1.87 & +5.5 \\
\hline $45-59$ & 3431 & 709972 & 4.83 & -1.3 \\
\hline 2011 & & & & \\
\hline Total & 5459 & 1834093 & 2.98 & -1.3 \\
\hline Gender & & & & \\
\hline Men & 1638 & 916408 & 1.79 & -1.7 \\
\hline Women & 3821 & 917685 & 4.16 & -1.4 \\
\hline Age (years & & & & \\
\hline $20-44$ & 1995 & 1121717 & 1.78 & -5.1 \\
\hline $45-59$ & 3464 & 712376 & 4.86 & +0.6 \\
\hline
\end{tabular}
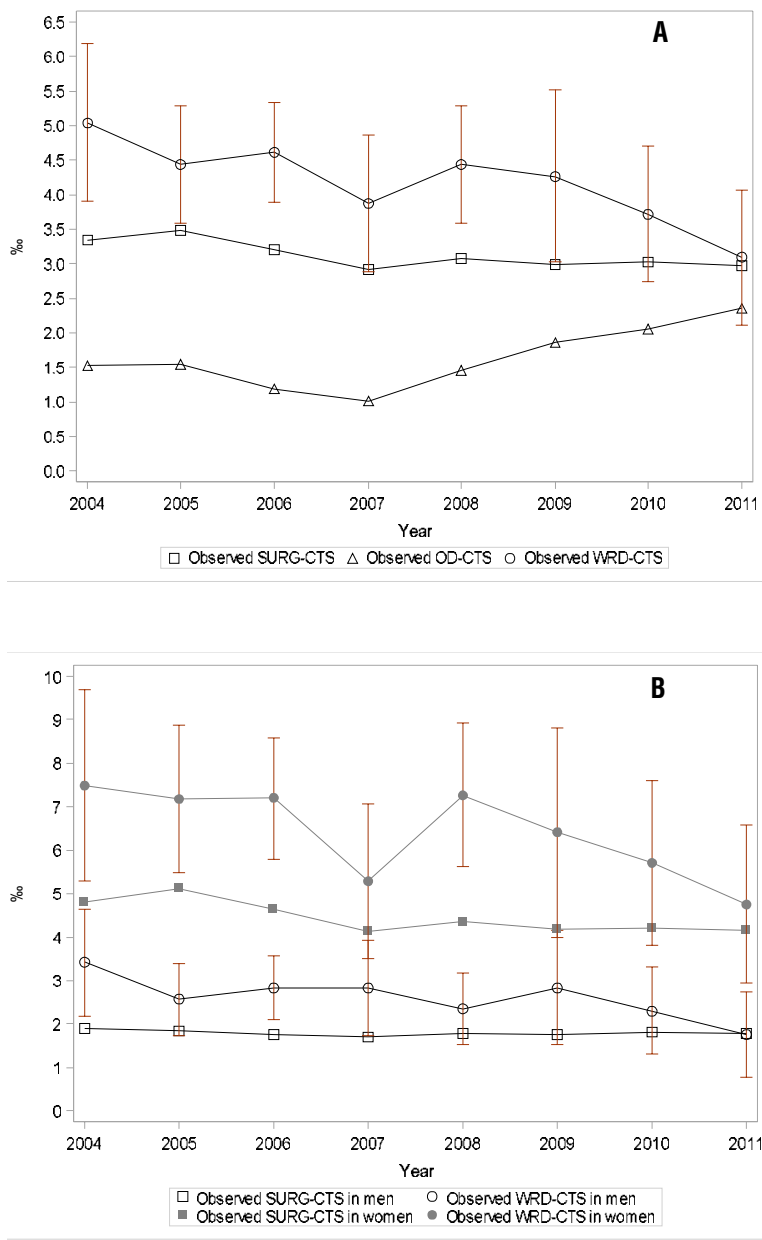

Figure 1. Observed time trends in incidence of SURG-CTS (squares) and OD-CTS (triangles) and prevalence of WRD-CTS (circles) per 1000 person-years in the population of the Pays de la Loire of working age between 2004 and 2011; (A) both genders, (B) men and women*

correlation test: $+0.500, \mathrm{P}=0.083$ ). The negative binomial regression model with cubic spline curves showed a statistically significant decrease before $2007[-3.81 \%$, $(95 \%$ CI $-4.20--3.43 \%), \mathrm{P}<0.001)$ and a statistically significant increase after 2007 [+6.63\% (95\% CI 5.37$7.88 \%), \mathrm{P}<0.001]$ in the annual incidence of OD-CTS (figure $2 b$ ). Wide annual percent change (ranging from $-24 \%$ in 2006 to $+43 \%$ in 2008 ) occurred, whether the reference population was the whole salaried population or specific industry sectors.

\section{Trends in prevalence of WRD-CTS}

The number of OP participating in the surveillance program (range 106-256), and consequently the number of workers examined, varied each semester (table 3 ). The annual number of WRD-CTS cases diagnosed varied (range 38-158) in relation to the number of salaried 
workers surveyed during different 2 -week periods. The prevalence rate of WRD-CTS decreased from 5.04 (95\% CI 3.90-6.19) to $3.08(95 \%$ CI 2.11-4.06) per 1000 employed person-years between 2004 and 2011 (Kendall correlation test: $-0.786, \mathrm{P}=0.007)$, with wide annual percent change (-17\% in 2011 and $-16 \%$ in 2007 to $+15 \%$ in 2008) (figure 1a). The negative binomial regression model with cubic spline curves showed non-significant tri-phasic trends: a decrease before 2007 [-0.51\% (95\% CI -1.40-0.38\%), $\mathrm{P}=0.26)$, an increase between 2007 and 2009 [2.25\% (95\% CI -3.19-7.40\%), $\mathrm{P}=0.41]$ and a decline after 2009 [-3.35\% (95\% CI -25.42-14.84\%), $\mathrm{P}=0.74]$ in the annual incidence of WRD-CTS (figure 2c). The prevalence rate and decreasing trends were higher among women (from 7.48 to 4.75 cases per 1000 person-years, overall decrease of $37 \%$ ) than men (from 3.41 to 1.75 cases per 1000 person-years, overall decrease of $49 \%$ ) (figure $1 \mathrm{~b}$ ). The decreasing trends according to occupational categories were less consistent because of wide year to year fluctuations in the worker populations examined.

\section{Discussion}

Using three independent population-based data sources on the frequency of CTS, we revealed a general decreasing annual time trend for CTS over an 8-year period for the incidence of SURG-CTS in the general population and the prevalence of WRD-CTS registered by an active disease surveillance program. In contrast, the annual time trend of OD-CTS varied during the study period, with an observed decreasing trend before 2007 followed by an increasing trend after 2007 .

One of the strengths of the present study was the use of three CTS case definitions (22) based on independent sources of data. Some limitations need to be taken into consideration when interpreting the results. The hospital discharge database cannot identify occupational status, but about $75 \%$ of the region's inhabitants aged 20-59 years were currently working (19). No information was available on the interval between the onset of symptoms of CTS and the surgical treatment. Data from a pilot study described above on SURG-CTS conducted in the same region in 2002-2003 estimated that the mean interval between the onset of the hand symptoms and the date of surgery was 3 to 4 years (unpublished data). The regional database of the national health insurance system used for OD statistics covered only $76 \%$ of the region's working population (17), but this percentage remained stable during the study period. This insurance system excluded non-salaried workers and certain occupations at high risk of CTS, such as agricultural workers (17). OD-
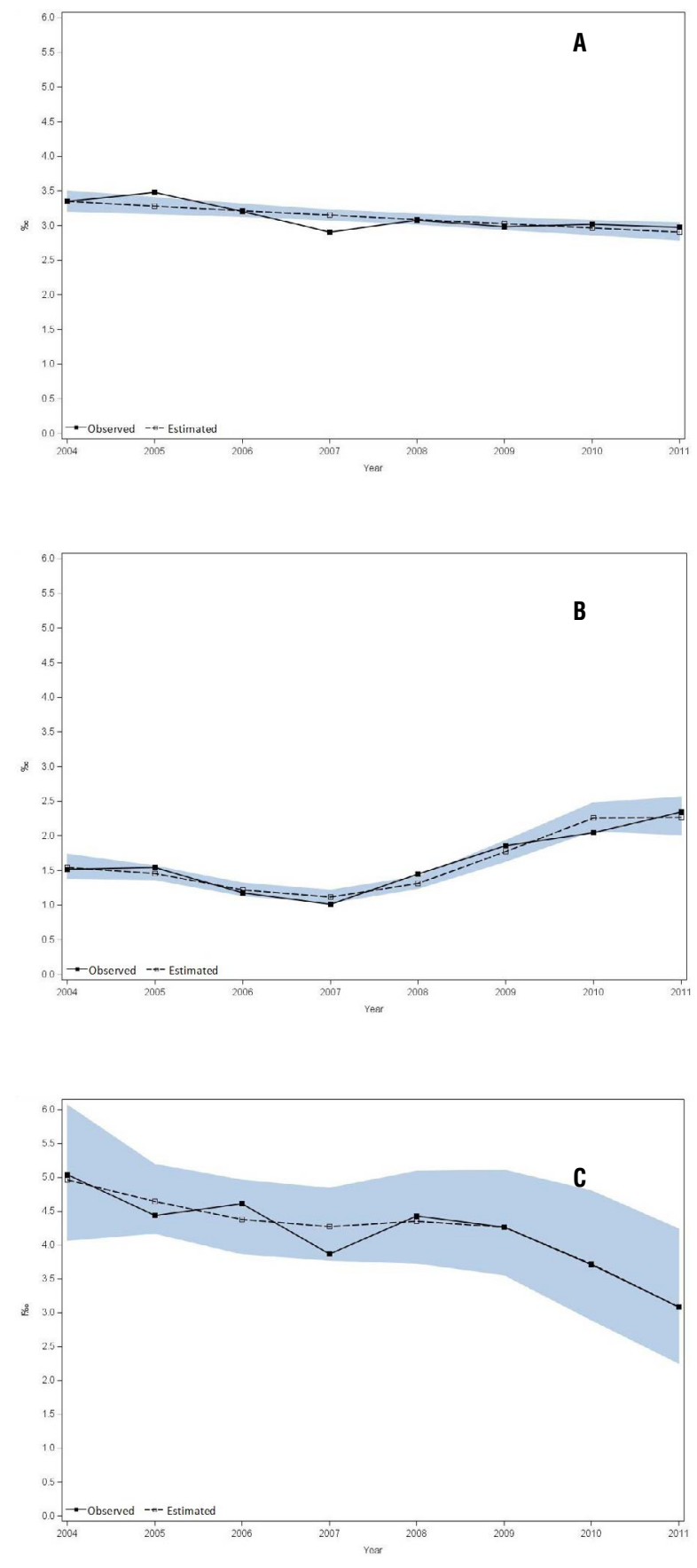

Figure 2. Observed (full squares "Observed") and estimated (open squares "Estimated") annual incidence/prevalence changes of $(A)$ SURG-CTS. Year: continuous variable; (B) OD-CTS, year: cubic spline with one knot in 2007; and (C) WRD-CTS, year: cubic spline with two knots in 2007 and 2009 per 1000 person-years in the Pays de la Loire region between 2004 and 2011 according to negative binomial regression models. 
Table 2. Annual incidence rate (IR) of carpal tunnel syndrome compensated for as occupational disease (OD-CTS) per 1000 personyears in salaried workers. Pays de la Loire, France, 2004-2011.

\begin{tabular}{|c|c|c|c|c|}
\hline Year & OD-CTS a & $\begin{array}{c}\text { Social } \\
\text { insurance }{ }^{b}\end{array}$ & IR & $\begin{array}{c}\text { Annual } \\
\text { change } \\
(\%)\end{array}$ \\
\hline \multicolumn{5}{|l|}{2004} \\
\hline Total & 1464 & 962963 & 1.52 & \\
\hline \multicolumn{5}{|l|}{ Gender } \\
\hline Men & 504 & & & \\
\hline Women & 960 & & & \\
\hline \multicolumn{5}{|l|}{ Industry sector ${ }^{\mathrm{C}}$} \\
\hline AA - Manufacturing & 168 & 125247 & 1.34 & \\
\hline BB - Construction & 49 & 76159 & 0.64 & \\
\hline $\begin{array}{l}\text { DD - Food industry and } \\
\text { related services }\end{array}$ & 255 & 131543 & 1.94 & \\
\hline \multicolumn{5}{|l|}{2005} \\
\hline Total & 1534 & 991893 & 1.55 & +1.7 \\
\hline \multicolumn{5}{|l|}{ Gender } \\
\hline Men & 523 & & & \\
\hline Women & 1011 & & & \\
\hline \multicolumn{5}{|l|}{ Industry sector c } \\
\hline AA - Manufacturing & 135 & 125015 & 1.08 & -19.5 \\
\hline BB - Construction & 66 & 81172 & 0.81 & +26.4 \\
\hline $\begin{array}{l}\text { DD - Food industry and } \\
\text { related services }\end{array}$ & 276 & 130574 & 2.11 & +9.0 \\
\hline $\mathrm{HH}$ - Services industries ${ }^{d}$ & 40 & 174036 & 0.23 & +6.4 \\
\hline \multicolumn{5}{|l|}{2006} \\
\hline Total & 1492 & 1267149 & 1.18 & -23.9 \\
\hline \multicolumn{5}{|l|}{ Gender } \\
\hline Men & 504 & & & \\
\hline Women & 988 & & & \\
\hline \multicolumn{5}{|l|}{ Industry sector ${ }^{c}$} \\
\hline AA - Manufacturing & 178 & 124196 & 1.43 & +32.7 \\
\hline BB - Construction & 114 & 86483 & 1.32 & +62.1 \\
\hline $\begin{array}{l}\text { DD - Food industry and } \\
\text { related services }\end{array}$ & 400 & 129436 & 3.09 & +46.2 \\
\hline $\mathrm{HH}$ - Services industries ${ }^{d}$ & 62 & 169386 & 0.37 & +59.3 \\
\hline \multicolumn{5}{|l|}{2007} \\
\hline Total & 1279 & 1263558 & 1.01 & -14.0 \\
\hline \multicolumn{5}{|l|}{ Gender } \\
\hline Men & 425 & & & \\
\hline Women & 854 & & & \\
\hline \multicolumn{5}{|l|}{ Industry sector c } \\
\hline AA - Manufacturing & 130 & 123385 & 1.05 & -26.5 \\
\hline BB - Construction & 99 & 101113 & 0.98 & -25.7 \\
\hline $\begin{array}{l}\text { DD - Food industry and } \\
\text { related services }\end{array}$ & 336 & 130169 & 2.58 & -16.5 \\
\hline $\mathrm{HH}$ - Services industries ${ }^{d}$ & 74 & 191291 & 0.39 & +5.7 \\
\hline
\end{tabular}

continued
CTS cases were registered anonymously in the regional database. Because of the France's worker compensation law, cases of bilateral CTS were counted as two cases, whether workers claimed compensation simultaneously for both wrists or not. However, we have no information suggesting that the ratio of unilateral to bilateral cases of CTS changed in the working population over the study period (6). The registration of WRD-CTS relied on the personal judgement of the OP on the diagnosis and work relatedness of CTS in the absence of French national guidelines (20). However, most of the OP had been involved in the large COSALI cohort of salaried
Table 2. continued

\begin{tabular}{|c|c|c|c|c|}
\hline \multicolumn{5}{|l|}{2008} \\
\hline Total & 1556 & 1073815 & 1.45 & +43.2 \\
\hline \multicolumn{5}{|l|}{ Gender } \\
\hline Men & 535 & & & \\
\hline Women & 1021 & & & \\
\hline \multicolumn{5}{|l|}{ Industry sector c } \\
\hline AA - Manufacturing & 203 & 123050 & 1.65 & +56.6 \\
\hline BB - Construction & 128 & 104792 & 1.22 & +24.8 \\
\hline $\begin{array}{l}\text { DD - Food industry and } \\
\text { related services }\end{array}$ & 428 & 131575 & 3.25 & +26.0 \\
\hline $\mathrm{HH}$ - Services industries ${ }^{d}$ & 63 & 186884 & 0.34 & -12.9 \\
\hline \multicolumn{5}{|l|}{2009} \\
\hline Total & 1915 & 1031275 & 1.86 & +28.2 \\
\hline \multicolumn{5}{|l|}{ Gender } \\
\hline Men & 676 & & & \\
\hline Women & 1239 & & & \\
\hline \multicolumn{5}{|l|}{ Industry sector c } \\
\hline AA - Manufacturing & 250 & 116804 & 2.14 & +29.7 \\
\hline BB - Construction & 149 & 104917 & 1.42 & +16.3 \\
\hline $\begin{array}{l}\text { DD - Food industry and } \\
\text { related services }\end{array}$ & 594 & 132736 & 4.48 & +37.6 \\
\hline $\mathrm{HH}$ - Services industries ${ }^{d}$ & 96 & 190524 & 0.50 & +49.5 \\
\hline \multicolumn{5}{|l|}{2010} \\
\hline Total & 2052 & 1003537 & 2.04 & +10.1 \\
\hline \multicolumn{5}{|l|}{ Gender } \\
\hline Men & 737 & & & \\
\hline Women & 1315 & & & \\
\hline \multicolumn{5}{|l|}{ Industry sector ${ }^{\mathrm{C}}$} \\
\hline AA - Manufacturing & 283 & 112107 & 2.52 & +17.9 \\
\hline BB - Construction & 178 & 104554 & 1.70 & +19.9 \\
\hline $\begin{array}{l}\text { DD - Food industry and } \\
\text { related services }\end{array}$ & 553 & 135617 & 4.08 & -8.9 \\
\hline $\mathrm{HH}$ - Services industries ${ }^{d}$ & 86 & 192951 & 0.45 & -11.5 \\
\hline \multicolumn{5}{|l|}{2011} \\
\hline Total & 2312 & 986493 & 2.34 & +14.6 \\
\hline \multicolumn{5}{|l|}{ Gender } \\
\hline Men & 844 & & & \\
\hline Women & 1468 & & & \\
\hline \multicolumn{5}{|l|}{ Industry sector ${ }^{\mathrm{c}}$} \\
\hline AA - Manufacturing & 270 & 112936 & 2.39 & -5.3 \\
\hline BB - Construction & 245 & 106453 & 2.30 & +35.2 \\
\hline $\begin{array}{l}\mathrm{DD}-\text { Food industry and } \\
\text { related services }\end{array}$ & 620 & 138241 & 4.48 & +10.0 \\
\hline $\mathrm{HH}$ - Services industries ${ }^{d}$ & 75 & 200040 & 0.37 & -15.9 \\
\hline
\end{tabular}

workers from the Pays de la Loire region (cohorte de salariés Ligériens), and were trained in the application of the recommendations of the European Consensus Criteria Document for the Evaluation of the Work-relatedness of MSD (23). In France, OP regularly perform risk assessments in the workplace, providing them with better opportunities to assess the relationships between CTS and work-related risk factors than other physicians (20). We computed annual prevalence rates rather than incidence rates for WRD-CTS since symptoms of CTS may have occurred several months before the inclusion of workers in the WRD program. It was extremely 
Table 3. Annual prevalence of work-related carpal tunnel syndrome (WRD-CTS) per 1000 person-years in salaried workers. Pays de la Loire, France, 2004-2011. [OP=occupational physician; WRD=work-related disease; NA=not available; 95\% Cl=95\% confidence interval.]

\begin{tabular}{|c|c|c|c|c|c|c|c|c|c|c|c|c|}
\hline & \multicolumn{2}{|c|}{$\mathrm{OP}$} & \multirow{2}{*}{$\begin{array}{c}\begin{array}{c}\text { Workers } \\
\text { surveyed }\end{array} \\
N\end{array}$} & \multirow{2}{*}{$\begin{array}{c}\begin{array}{c}\text { All } \\
\text { WRD }\end{array} \\
N\end{array}$} & \multicolumn{2}{|c|}{ WRD-CTS } & \multicolumn{2}{|c|}{$\begin{array}{c}\text { Prevalence } \\
\text { rate }^{a}\end{array}$} & \multirow{2}{*}{$\begin{array}{c}\text { Annual } \\
\text { change } \\
(\%)\end{array}$} & \multicolumn{2}{|c|}{$\begin{array}{c}\text { Prevalence } \\
\text { rate }^{b}\end{array}$} & \multirow{2}{*}{$\begin{array}{c}\text { Annual } \\
\text { change } \\
(\%)\end{array}$} \\
\hline & $\mathrm{N}$ & $\%$ & & & $\mathrm{~N}$ & $\% c$ & $P(\%)$ & $95 \% \mathrm{Cl}$ & & $P(\%)$ & $95 \% \mathrm{Cl}$ & \\
\hline \multicolumn{13}{|l|}{2004} \\
\hline Total & 203 & 46 & $14677 d$ & 259 & 74 & 28.57 & 17.65 & $15.52-19.78$ & & 5.04 & $3.90-6.19$ & - \\
\hline \multicolumn{13}{|l|}{ Gender } \\
\hline Men & & & 8789 & 142 & 30 & 21.13 & 16.16 & $13.52-18.79$ & & 3.41 & $2.19-4.63$ & \\
\hline Women & & & 5884 & 117 & 44 & 37.61 & 19.88 & $16.32-23.45$ & & 7.48 & $5.28-9.68$ & \\
\hline \multicolumn{13}{|l|}{ Major job groups } \\
\hline Associate professional \& higher jobs ${ }^{\text {e }}$ & & & NA & & & & & & & & & \\
\hline Low grade white-collar workers ${ }^{f}$ & & & NA & & & & & & & & & \\
\hline Blue-collar workers ${ }^{g}$ & & & NA & & & & & & & & & \\
\hline \multicolumn{13}{|l|}{2005} \\
\hline Total & 244 & 44 & $23664^{d}$ & 510 & 105 & 20.59 & 21.55 & $19.70-23.40$ & +22.13 & 4.44 & $3.59-5.28$ & -12.0 \\
\hline \multicolumn{13}{|l|}{ Gender } \\
\hline Men & & & 14056 & 288 & 36 & 12.50 & 20.49 & $18.15-22.83$ & +26.82 & 2.56 & $1.73-3.40$ & -25.0 \\
\hline Women & & & 9608 & 222 & 69 & 31.08 & 23.11 & $20.20-26.11$ & +16.20 & 7.18 & $5.49-8.87$ & -4.0 \\
\hline \multicolumn{13}{|l|}{ Major job groups } \\
\hline Associate professional \& higher jobs ${ }^{e}$ & & & NA & & & & & & & & & \\
\hline Low grade white-collar workers ${ }^{f}$ & & & NA & & & & & & & & & \\
\hline Blue-collar workers ${ }^{g}$ & & & NA & & & & & & & & & \\
\hline \multicolumn{13}{|l|}{2006} \\
\hline Total & 256 & 47 & $34261^{d}$ & 760 & 158 & 20.79 & 22.18 & $20.62-23.74$ & +2.93 & 4.61 & $3.89-5.33$ & +3.9 \\
\hline \multicolumn{13}{|l|}{ Gender } \\
\hline Men & & & 20136 & 372 & $57)$ & 15.32 & 18.47 & $16.61-20.33$ & -9.83 & 2.83 & $2.10-3.56$ & +10.5 \\
\hline Women & & & 14042 & 388 & 101 & 26.03 & 27.63 & $24.92-30.34$ & +19.59 & 7.19 & $5.79-8.59$ & +0.2 \\
\hline \multicolumn{13}{|l|}{ Major job groups } \\
\hline Associate professional \& higher jobs ${ }^{e}$ & & & NA & & & & & & & & & \\
\hline Low grade white-collar workers ${ }^{f}$ & & & NA & & & & & & & & & \\
\hline Blue-collar workers ${ }^{g}$ & & & NA & & & & & & & & & \\
\hline \multicolumn{13}{|l|}{2007} \\
\hline Total & 191 & 37 & $15247^{\text {h }}$ & 404 & 59 & 14.60 & 26.50 & $23.95-29.05$ & +19.45 & 3.87 & $2.88-4.86$ & -16.1 \\
\hline \multicolumn{13}{|l|}{ Gender } \\
\hline Men & & & 8823 & 228 & 25 & 10.96 & 25.84 & $22.53-29.15$ & +39.88 & 2.83 & $1.72-3.94$ & +0.1 \\
\hline Women & & & 6424 & 176 & 34 & 19.32 & 27.40 & $23.41-31.39$ & -0.85 & 5.29 & $3.52-7.07$ & -26.4 \\
\hline Major job groups & & & & & & & & & & & & \\
\hline Associate professional \& higher jobs ${ }^{e}$ & & & 3548 & 28 & 2 & 7.14 & 7.89 & $4.98-10.80$ & & 0.56 & $0.07-2.03$ & \\
\hline Low grade white-collar workers ${ }^{f}$ & & & 4240 & 84 & 7 & 8.33 & 19.81 & $15.62-24.01$ & & 1.65 & $0.66-3.40$ & \\
\hline Blue-collar workers ${ }^{g}$ & & & 7257 & 292 & 50 & 17.12 & 40.24 & $35.72-44.76$ & & 6.89 & $4.99-8.79$ & \\
\hline 2008 & & & & & & & & & & & & \\
\hline Total & 204 & 41 & $23698 d$ & 600 & 105 & 17.50 & 25.32 & 23.32-27.32 & -4.45 & 4.43 & $3.59-5.28$ & +14.5 \\
\hline Gender & & & & & & & & & & & & \\
\hline Men & & & 13648 & 301 & 32 & 10.63 & 22.05 & $19.59-24.52$ & -14.65 & 2.34 & $1.53-3.16$ & -17.3 \\
\hline Women & & & 10044 & 299 & 73 & 24.41 & 29.77 & $26.45-33.09$ & +8.66 & 7.27 & $5.61-8.93$ & +37.3 \\
\hline Major job groups & & & & & & & & & & & & \\
\hline Associate professional \& higher jobs ${ }^{\text {e }}$ & & & 5529 & 60 & 4 & 6.67 & 10.85 & $8.12-13.58$ & +37.51 & 0.72 & $0.20-1.85$ & +28.3 \\
\hline Low grade white-collar workers ${ }^{f}$ & & & 6443 & 138 & 31 & 22.46 & 21.42 & $17.88-24.95$ & +8.11 & 4.81 & $3.12-6.50$ & +191.4 \\
\hline Blue-collar workers ${ }^{g}$ & & & 11554 & 402 & 70 & 17.41 & 34.79 & $31.45-38.13$ & -13.53 & 6.06 & $4.64-7.47$ & -12.1 \\
\hline
\end{tabular}

rare for workers to be examined more than once by the WRD surveillance system during the study period, and no information suggested any temporal changes in the mean duration of symptoms before the finding of WRDCTS. In consequence, trends in prevalence are likely to accurately reflect trends in the incidence of WRD-CTS. Selection bias could have occurred since workers were not randomly included during the selected 2-week periods. In contrast to hospital discharges and workers' compensation claims, the trends in WRD-CTS observed were independent of workers' propensity to seek treatment for CTS and to attribute CTS to occupation.
The decrease of SURG-CTS and, to a lesser extent, WRD-CTS in the Pays de la Loire region is consistent with other recent multiple-source surveillance studies reporting declining rates of non-traumatic MSD in North America and Europe, despite different study designs and survey populations. Using broader definitions, including both UE-MSD and back disorders, Mustard et al (14) reported a decrease in the incidence of work-related MSD during a similar period according to emergency department administrative records, lost-time workers' compensation claims and participants in a national health interview survey in Ontario (Canada) (range -3.4\%, 7.2\% 
Table 3. Continued.

\begin{tabular}{|c|c|c|c|c|c|c|c|c|c|c|c|c|}
\hline & \multicolumn{2}{|c|}{$\mathrm{OP}$} & \multirow{2}{*}{$\begin{array}{c}\text { Workers } \\
\text { surveyed } \\
\mathrm{N}\end{array}$} & \multirow{2}{*}{$\begin{array}{c}\begin{array}{c}\text { All } \\
\text { WRD }\end{array} \\
\mathrm{N}\end{array}$} & \multicolumn{2}{|c|}{ WRD-CTS } & \multicolumn{2}{|c|}{$\begin{array}{l}\text { Prevalence } \\
\text { rate }^{\text {a }}\end{array}$} & \multirow{2}{*}{$\begin{array}{c}\text { Annual } \\
\text { change } \\
(\%)\end{array}$} & \multicolumn{2}{|c|}{$\begin{array}{c}\text { Prevalence } \\
\text { rate }^{\mathrm{b}}\end{array}$} & \multirow{2}{*}{$\begin{array}{c}\text { Annual } \\
\text { change } \\
(\%)\end{array}$} \\
\hline & $\mathrm{N}$ & $\%$ & & & N & $\%{ }^{c}$ & $P(\%)$ & $95 \% \mathrm{Cl}$ & & $\mathrm{P}(\% 0)$ & $95 \% \mathrm{Cl}$ & \\
\hline \multicolumn{13}{|l|}{2009} \\
\hline Total & 142 & 29 & $10549^{h}$ & 308 & 45 & 14.61 & 29.20 & $25.98-32.41$ & +15.32 & 4.27 & $3.02-5.51$ & -3.7 \\
\hline \multicolumn{13}{|l|}{ Gender } \\
\hline Men & & & 6337 & 153 & 18 & 11.76 & 24.14 & $20.36-27.92$ & +9.47 & 2.84 & $1.53-4.15$ & +21.2 \\
\hline Women & & & 4212 & 155 & 27 & 17.42 & 36.80 & $31.11-42.49$ & +23.62 & 6.41 & $4.00-8.82$ & -11.8 \\
\hline \multicolumn{13}{|l|}{ Major job groups } \\
\hline Associate professional \& higher jobs ${ }^{e}$ & & & 2565 & 25 & 2 & 8.00 & 9.75 & $5.94-13.55$ & -10.19 & 0.78 & $0.09-2.81$ & +7.8 \\
\hline Low grade white-collar workers ${ }^{\dagger}$ & & & 2829 & 77 & 12 & 15.58 & 27.22 & $21.22-33.21$ & +27.08 & 4.24 & $1.85-6.64$ & -11.8 \\
\hline Blue-collar workers 9 & & & 5141 & 205 & 31 & 15.12 & 39.88 & $34.53-45.22$ & +14.61 & 6.03 & $3.91-8.15$ & -0.5 \\
\hline \multicolumn{13}{|l|}{2010} \\
\hline Total & 140 & 29 & $14795^{d}$ & 389 & 55 & 14.14 & 26.29 & $23.71-28.87$ & -9.95 & 3.72 & $2.74-4.70$ & -12.9 \\
\hline \multicolumn{13}{|l|}{ Gender } \\
\hline Men & & & 8672 & 216 & 20 & 9.26 & 24.91 & 21.63-28.19 & +3.16 & 2.31 & $1.30-3.32$ & -18.8 \\
\hline Women & & & 6123 & 173 & 35 & 20.23 & 28.25 & $24.10-32.40$ & -23.22 & 5.72 & $3.83-7.60$ & -10.8 \\
\hline \multicolumn{13}{|l|}{ Major job groups } \\
\hline Associate professional \& higher jobs ${ }^{\mathrm{e}}$ & & & 3668 & 38 & 2 & 5.26 & 10.36 & $7.08-13.64$ & +6.29 & 0.55 & $0.07-1.97$ & -30.1 \\
\hline Low grade white-collar workers ${ }^{\dagger}$ & & & 3934 & 87 & 16 & 18.39 & 22.11 & $17.52-26.71$ & -18.75 & 4.07 & $2.08-6.06$ & -4.1 \\
\hline Blue-collar workers ${ }^{g}$ & & & 7168 & 264 & 37 & 14.02 & 36.83 & $32.47-41.19$ & -7.64 & 5.16 & $3.50-6.82$ & -14.4 \\
\hline \multicolumn{13}{|l|}{2011} \\
\hline Total & 106 & 23 & $12319 d$ & 326 & 38 & 11.66 & 26.46 & $23.63-29.30$ & 0.65 & 3.08 & $2.11-4.06$ & -17.0 \\
\hline \multicolumn{13}{|l|}{ Gender } \\
\hline Men & & & 6841 & 161 & 12 & 7.45 & 23.53 & $19.94-27.13$ & -5.51 & 1.75 & $0.76-2.75$ & -23.9 \\
\hline Women & & & 5478 & 165 & 26 & 15.76 & 30.12 & $25.59-34.65$ & 6.61 & 4.75 & $2.93-6.57$ & -17.0 \\
\hline \multicolumn{13}{|l|}{ Major job groups } \\
\hline Associate professional \& higher jobs $\mathrm{e}$ & & & 2838 & 29 & 3 & 10.34 & 10.22 & $6.52-13.92$ & -1.36 & 1.06 & $0.22-3.09$ & +93.9 \\
\hline Low grade white-collar workers ${ }^{\dagger}$ & & & 3731 & 72 & 9 & 12.50 & 19.30 & $14.88-23.71$ & -12.74 & 2.41 & $1.10-4.57$ & -40.7 \\
\hline Blue-collar workers ${ }^{g}$ & & & 5737 & 225 & 26 & 11.56 & 39.22 & $34.20-44.24$ & +6.49 & 4.53 & $2.79-6.27$ & -12.2 \\
\hline
\end{tabular}

a Prevalence rate of all WRD per 1000 employed person-years.

b Prevalence rate of all WRD-CTS per 1000 employed person-years;

c Percentage of WRD-CTS compared to all WRD.

d Two 2-week periods during the year.

e French PCS codes corresponding to ISCO-08 1-3 major groups

${ }^{f}$ French PCS codes corresponding to ISCO-08 4-5 major groups

9 French PCS codes corresponding to ISC0-08 6-8 major groups

${ }^{\mathrm{h}}$ One 2-week period during the year.

and $-5.3 \%$, respectively). The comparison of surveillance data using various sentinel events across ten European countries (MODERNET network) partly confirmed the decreasing trend in the European Union by showing wide variations in trends of incidence of CTS within and between countries from 2000 to 2012 (15). In the US, incidence rate estimates from the Bureau of Labor Statistics (BLS) Survey of Occupational Injuries and Illnesses (SOII) for employer-reported work-related CTS resulting in days away from work ranged from a high of 2.5 per 10000 full-time workers to 1.0 per 10000 fulltime workers between 2003 and 2009 (24). However, the 12-month prevalence of self-reported clinician-diagnosed CTS in the general population was $3.1 \%$ in the 2010 National Health Interview Survey in the US and seemed to be more prevalent and more widely attributed to work by healthcare providers than in 1988 (24).

Our results should be interpreted with caution (16) since several non-occupational and occupational factors might have influenced the declining rates of SURG-CTS and WRD-CTS and the contrasting rate of OD-CTS.
Some non-occupational factors, such as modifications of medical access to hand surgery and/or OP practice over the study period cannot be excluded. However, we have no information suggesting a lower possibility of access to surgical centers in the region since the number of surgical centers and hand surgeons remained stable and patients' financial reimbursement for surgery had not changed during the study period. We have no information indicating changes in surgeons' practice that might have modified their choice of surgical rather than conservative treatment of CTS. Although we cannot exclude the possibility of reduced access to surgical centers, this phenomenon alone probably cannot explain the decreasing trends in SURG-CTS incidence rate observed over the 8-year period.

The contrasting bi-phasic trends in OD-CTS observed in the Pays de la Loire region over the study period should be interpreted with caution since they could reflect lower incidence of WRD-CTS and/or lower rate of declaration of OD-CTS before 2007, and the opposite thereafter. Such administrative data are gener- 
ally considered to underestimate the incidence of WRDCTS $(17,25)$, and the rate of under-reporting of CTS has been estimated at 59\% (range 52-64\%) in France by comparing compensated cases and cases identified by the WRD program (17). No data are available to assess variations in under-reporting of CTS in the region over the period. We cannot exclude the possibility that some workers would have been less willing to file a claim for CTS because they feared losing their jobs or wanted to avoid reprisals, and that such fears may have increased following the economic crisis of 2008 (16). Nevertheless, the effect of the crisis on the employment rate was weak before 2010, and any fear of reprisals would have led to a decreasing trend. Information campaigns on UE-MSD, launched at the regional level in 2006 and national level in 2008 (6), might have had the opposite effect by encouraging workers suffering from CTS to file claims for compensation. French Ministry of Labor assessments showed that these campaigns had a high impact on the awareness of UE-MSD in the general population. We can therefore hypothesize that these campaigns could have increased workers' propensity to claim compensation after 2008 and might explain the contrasting trends in SURG-CTS and OD-CTS. Fewer OP were involved in the region's surveillance networks during this period; though it seems unlikely, we cannot exclude the possibility that this decrease in the number of physicians resulted in changes in ascertainment of CTS during surveillance examinations that could have lowered the incidence rates of WRD-CTS over time. Trends observed in WRD-CTS might partly reflect changes in the propensity of OP to attribute CTS to occupation rather than other risks (16). However, OP awareness regarding the work-relatedness of CTS did not decrease during the study period (6) and does not explain the general decreasing trend observed. Finally, in view of the many factors influencing workers' propensity to claim for compensation, namely after the economic crises of 2008, and the consistent declining trends of SURG-CTS and WRD-CTS observed over the study period, we consider that the declining trend in incidence/ prevalence of CTS is the actual trend in this population.

Several non-occupational and occupational factors probably contributed to the declining rates of CTS in the Pays de la Loire region. Reduction in the prevalence of well-documented risk factors for CTS in the population of working age, such as obesity and diabetes mellitus $(7,8)$, might be related to the decline in the incidence of CTS, whether cases were attributable to work or not. However, the prevalence of diabetes mellitus (requiring use of prescription drugs), estimated to be 3.6 cases per 100 inhabitants in the Pays de la Loire in 2009, increased over the last decade in this region (26) and cannot explain the decreasing trends in incidence of CTS. According to the obesity surveys (OBEPI) con- ducted every three years among French adults, obesity in the Pays de la Loire region increased drastically between 2003 and $2009(+33 \%)$ and decreased moderately between 2009 and $2012(-11.3 \%)$ (27). Even if the reduction in obesity after 2009 contributed to lower incidence of CTS, it probably occurred too late to have had a significant effect before 2012 because of the waiting time for surgery. Changes in the prevalence of obesity in this region are thus unlikely to account for the decline in incidence of CTS observed.

As in other European countries, French governmental action plans for the improvement of occupational health were implemented in 2005-2009, and modification of occupational factors during the study period should be considered as a potential explanation for the observed decline in CTS (6). Information campaigns on UE-MSD raised awareness in the population, including among employers and physicians. This campaign encouraged preventive action in the workplace that was expected to improve the ergonomic conditions of highly exposed workers and/or to reduce the number of workers exposed to high levels of mechanical workload. Such interventions could have decreased exposure to work-related risk factors for CTS, mainly mechanical loading, and thus led to consistently declining rates of CTS at the population level. These plans and campaigns were not formally evaluated at regional and national levels. Findings from the COSALI cohort, comprising a representative sample of the region's salaried workers, agreed with other surveys of working conditions in France and Europe in revealing lower exposure to mechanical loads, contrasting with greater exposure to time pressures and psychosocial constraints during the study period $(6,28-31)$. These contradictory trends did not provide any clear conclusion on the possible relationships between improved working conditions and decreasing trends in the incidence of CTS. Moreover, the impact of such improvements on the incidence of CTS would be limited, since it depended on the mean population attributable risk fraction of CTS to work which has been estimated at about $25 \%$ for SURG-CTS in this region (11). It seems likely that improvement in working conditions in the region probably accounted for some of the decreased incidence of CTS during the study period, but its effects in explaining the trends of CTS at a population level were probably limited. Other explanations should be considered when evaluating whether the trends in incidence observed in the sentinel events reflected an improvement of working conditions. First of all, declining rates might reflect effects of the economic situation rather than a true reduction in work-related risk (16). Some industry sectors at high risk of UE-MSD declined over the period, such as the manufacturing industry $(-10 \%)$ and agriculture $(-12 \%)$ sectors, while sectors at lower risk increased little, such as the service 
sectors $(+6 \%)(19)$. However, despite the major world economic crisis that occurred in 2008 , the rates of unemployment (according to the ILO definition) increased little [from 7.2 in 2004 to $7.7 \%(+6.9 \%)$ in 2012] in the Pays de la Loire region (19). In the Ontario study, a large decrease was reported in all three data sources between 2008 and 2009, corresponding to the period of economic recession related to the global financial crisis (14). There was neither a dramatic fall in the sentinel events in the Pays de la Loire region, except for OD-CTS in 2008, nor a dramatic decrease in employment rates (except among those in temporary work) (19).

\section{Concluding remarks}

In conclusion, the Pays de la Loire surveillance program for UE-MSD showed that different and independent data sources are useful to describe epidemiologic trends at a regional level. The results confirmed recent findings in North America showing declining rates of CTS in the working age population between 2004 and 2011, except for compensated cases of CTS after 2007. Several nonoccupational and occupational factors have probably contributed to the declining rates of CTS in the Pays de la Loire region. However, more research and surveillance data are needed to assess whether and to what extent the declining rates of SURG-CTS and WRD-CTS are actually attributable to improvement in working conditions and/or to non-occupational factors.

\section{Acknowledgements}

We thank M Xavier Pascal for his contribution to the data analysis and M Desaubliaux from the Regional Social Security funds for his help in collecting data. The Pays de la Loire study received the approval of the French National Committee for Data Protection (CNIL: Commission Nationale Informatique et Liberté) and was supported by the French Public Health Agency, SaintMaurice, France (Grant 9/25/2002-5 "réseau expérimental de surveillance des troubles musculo-squelettiques).

\section{Conflict of interest}

The authors declare no conflicts of interest.

\section{References}

1. Hagberg M, Silverstein B, Wells R, Smith M, Hendrick H, Carayon P, et al. 2005. Work related musculoskeletal disorders (WMSDs): a reference book for prevention. London: Taylor \& Francis.
2. Roquelaure $\mathrm{Y}$, Ha C, Leclerc A, Touranchet A, Sauteron $\mathrm{M}$, Melchior $\mathrm{M}$, et al. Epidemiologic surveillance of upper-extremity musculoskeletal disorders in the working population. Arthritis Rheum. 2006;55:765-78. http://dx.doi. org/10.1002/art.22222.

3. Palmer KT, Harris EC, Coggon D. Carpal tunnel syndrome and its relation to occupation: a systematic literature review. Occup Med (Lond). 2007;57:57-66. http://dx.doi.org/10.1093/ occmed/kq1125.

4. Dale AM, Harris-Adamson C, Rempel D, Gerr F, Hegmann $\mathrm{K}$, Silverstein B, et al. Prevalence and incidence of carpal tunnel syndrome in US working populations: pooled analysis of six prospective studies. Scand J Work Environ Health. 2013;39:495-505. http://dx.doi.org/10.5271/sjweh.3351.

5. Tuppin P, Blotière PO, Weill A, Ricordeau P, Allemand H. Carpal tunnel syndrome surgery in France in 2008: patients' characteristics and management. Rev Neurol (Paris). 2011;167:905-15. (in French) http://dx.doi.org/10.1016/j. neurol.2011.05.010.

6. Brière J, Fouquet $\mathrm{N}, \mathrm{Ha} \mathrm{C}$, Imbernon $\mathrm{E}$, Plaine J, Rivière $\mathrm{S}$ et al. Occupational Health Indicators. Upper Limb Musculoskeletal Diseases in France. Saint-Maurice: Institut de veille sanitaire; 2015. p. 51.

7. Shiri R, Pourmemari MH, Falah-Hassani K, Viikari-Juntura E. The effect of excess body mass on the risk of carpal tunnel syndrome: a meta-analysis of 58 studies. Obes Rev. 2015;16:1094-104. http://dx.doi.org/10.1111/obr.12324.

8. Pourmemari MH, Shiri R. Diabetes as a risk factor for carpal tunnel syndrome: a systematic review and meta-analysis. Diabet Med. 2016;33:10-6. http://dx.doi.org/10.1111/ dme.12855.

9. Harris-Adamson C, Eisen EA, Dale AM, Evanoff B, Hegmann KT, Thiese MS, et al. Personal and workplace psychosocial risk factors for carpal tunnel syndrome: a pooled study cohort. Occup Environ Med. 2013;70:529-37. http://dx.doi. org/10.1136/oemed-2013-101365.

10. Bonfiglioli R, Mattioli S, Armstrong TJ, Graziosi F, Marinelli F, Farioli A, et al. Validation of the ACGIH TLV for hand activity level in the OCTOPUS cohort: a two-year longitudinal study of carpal tunnel syndrome. Scand J Work Environ Health. 2013;39:155-63. http://dx.doi.org/10.5271/ sjweh.3312.

11. Hamel J-F, Fouquet N, Ha C, Goldberg M, Roquelaure Y. Software for unbiased estimation of attributable risk. Epidemiol. 2012;23:646-7. http://dx.doi.org/10.1097/ EDE.0b013e318259c31c.

12. Roquelaure Y, Ha C, Fouquet N, Descatha A, Leclerc A, Goldberg M, et al. Attributable risk of carpal tunnel syndrome in the general population: implications for intervention programs in the workplace. Scand J Work Environ Health. 2009;35:342-8. http://dx.doi.org/10.5271/sjweh.1342.

13. Bhattacharya A. Costs of occupational musculoskeletal disorders (MSDs) in the United States. Int J Ind Ergon. 2014;44:448-54. http://dx.doi.org/10.1016/j. ergon.2014.01.008. 
14. Mustard CA, Chambers A, Ibrahim S, Etches J, Smith P. Time trends in musculoskeletal disorders attributed to work exposures in Ontario using three independent data sources, 2004-2011. Occup Environ Med. 2015;72: 252-7. http:// dx.doi.org/10.1136/oemed-2014-102442.

15. Stocks SJ, McNamee R, van der Molen HF, Paris C, Urban $\mathrm{P}$, Campo G, et al. Trends in incidence of occupational asthma, contact dermatitis, noise-induced hearing loss, carpal tunnel syndrome and upper limb musculoskeletal disorders in European countries from 2000 to 2012. Occup Environ Med. 2015;72:294-303. http://dx.doi.org/10.1136/ oemed-2014-102534

16. Vargas-Prada S. Work-related musculoskeletal disorders: are they truly declining? Occup Environ Med. 2015;72:239-40. http://dx.doi.org/10.1136/oemed-2014-102639.

17. Rivière $\mathrm{S}$, Penven E, Cadéac-Birman $\mathrm{H}$, Roquelaure $\mathrm{Y}$, Valenty M. Underreporting of musculoskeletal disorders in 10 regions in France in 2009. Am J Ind Med 2014;57:1174-80. http:// dx.doi.org/10.1002/ajim.22364.

18. Ha C, Roquelaure Y, Leclerc A, Touranchet A, Goldberg M, Imbernon E. The French Musculoskeletal Disorders Surveillance Program: Pays de la Loire Network. Occup Environ Med. 2009;66:471-9. http://dx.doi.org/10.1136/ oem.2008.042812.

19. National institute of statistics and economic studies (INSEE). Région des Pays de la Loire. Chiffres clés. Évolution et structure de la population: 2012. Available from: http://www. insee.fr/ (in French).

20. Valenty M, Homère J, Mevel M, Dourlat T, Garras L, Brom M, et al. (2012) Surveillance Program of Work-related Diseases (WRD) in France. Saf Health Work. 2012;3:67-70. http:// dx.doi.org/10.5491/SHAW.2012.3.1.67.

21. Greenland S. Dose-response and trend analysis in epidemiology: alternatives to categorical analysis. Epidemiology. 1995;6:35665. http://dx.doi.org/10.1097/00001648-199507000-00005.

22. Davis L, Wellman H, Punnett L. Surveillance of workrelated carpal tunnel syndrome in Massachusetts, 19921997: a report from the Massachusetts Sentinel Event Notification System for Occupational Risks (SENSOR).Am J Ind Med. 2001;39:58-71. http://dx.doi.org/10.1002/10970274(200101)39:1<58::AID-AJIM6>3.0.CO;2-3.
23. Sluiter JK, Rest KM, Frings-Dresen MH. Criteria document for evaluating the work-relatedness of upper-extremity musculoskeletal disorders. Scand J Work Environ Health. 2001;27 Suppl 1:1-102. http://dx.doi.org/10.5271/sjweh.637.

24. Luckhaupt SE, Dahlhamer JM, Ward BW, Sweeney MH, Sestito JP, Calvert GM. Prevalence and work-relatedness of carpal tunnel syndrome in the working population, United States, 2010 National Health Interview Survey. Am J Ind Med. 2013;56:615-24. http://dx.doi.org/10.1002/ajim.22048.

25. Stock S, Nicolakakis N, Raïq H, Messing K, Lippel K, Turcot A. Underreporting work absences for nontraumatic workrelated musculoskeletal disorders to workers' compensation: results of a 2007-2008 survey of the Québec working population. Am J Public Health. 2014;104: e94-e101. http:// dx.doi.org/10.2105/AJPH.2013.301562.

26. Observatoire Régional de la Santé des Pays de la Loire. La santé observée en 2012 : diabète. ORS. 2012; p. 3. (in French).

27. Inserm, Kanthar Health, Roche. Enquête épidémiologique nationale sur le surpoids et l'obésité. 2012; p. 60. (in French)

28. Petit A, Ha C, Bodin J, Rigouin P, Descatha A, Brunet R, et al. Risk factors for carpal tunnel syndrome related to the work organization: A prospective surveillance study in a large working population. Appl Ergon. 2015;47:1-10. http://dx.doi. org/10.1016/j.apergo.2014.08.007.

29. Bègue C, Fouquet N, Bodin J, Ramond-Roquin A, Huez JF, Bouton C, Roquelaure Y. Evolution of psychosocial factors at work in a French region. Occup Med. 2016;66:128-34. http:// dx.doi.org/10.1093/occmed/kqv147.

30. Arnaudo B, Leonard M, Sandret N, Cavet M, Coutrot T, Rivalin R, Thierus L. SUMER - Les risques professionnels en 2010: de fortes différences selon les secteurs d'activité. Référence en Santé au Travail. 2013;133:59-74. (In French)

31. Parent-Thirion A, Vermeylen G, Van Houten G, LylyYrjänäinen M, Biletta I, Cabrita J. Eurofound. Fifth European Working Conditions Survey. Overview report. Eurofound; 2012. report EF1182.

Received for publication: 9 December 2015 